\title{
Relative biological effectiveness (RBE) and dose rate dependent ratio of translocation to dicentric chromosome yield in ${ }^{252} \mathrm{Cf}$ neutrons
}

\author{
Kimio Tanaka* ${ }^{* 1}$, Natarajan Gajendran ${ }^{2,3}$ and Nanao Kamada ${ }^{4}$ \\ ${ }^{* 1}$ Department of Radiobiology, Institute for Environmental Sciences, \\ Hachazawa 2-121, Takahoko, Rokkasho, Kamikita, Aomori 039-3213, Japan. \\ ${ }^{2}$ Department of Cancer Cytogenetics, Research Institute for Radiation Biology and Medicine, Hiroshima \\ University. \\ ${ }^{3}$ Department of Biology, Eritrea Institute of Technology, Mainefhi, Eritrea. \\ ${ }^{4}$ Hiroshima Atomic Bomb Relief Foundation, 50-1, 3 Chome Asakita-ku, Hiroshima 739-1743, Japan \\ kmtanaka@ ies.or.jp*
}

Abstract: The relative biological effectiveness (RBE) of ${ }^{252} \mathrm{Cf}$ neutrons at different dose rates (2, $0.2 \& 0.02 \mathrm{cGy} / \mathrm{min}$ ) was assessed in human lymphocyte and bone marrow cells using cytogenetic end points (by Giemsa staining). The RBE values for 1 Gy of ${ }^{252} \mathrm{Cf}$ neutrons for chromosomal aberration yield in lymphocyte at the dose rates of 2 and $0.02 \mathrm{cGy} / \mathrm{min}$ were 3.3 and 12.0, respectively, in comparison to that of ${ }^{60} \mathrm{Co} \mathrm{Y}$ or ${ }^{137} \mathrm{Cs}$ y rays. RBE values of $\mathrm{Cf}(\mathrm{n})$ in human bone marrow were determined for the first time in the present study, and were 6.5 for chromatid-type and 4.4 for chromosome-type aberrations at the dose rate of $2 \mathrm{cGy} / \mathrm{min}$. These values were higher than those of lymphocytes obtained in the present study. As studied by FISH method, the exposure of ${ }^{252} \mathrm{Cf}$ neutrons and ${ }^{60} \mathrm{Co} \mathrm{Y}$ - and ${ }^{137} \mathrm{Cs} \mathrm{y}$ rays at different dose rates also revealed the fact that the ratio of the dicentric chromosome yield to the translocation yield was influenced by LET and dose rates. No dose rate effect was found for the induction of dicentric chromosome aberrations. But an increase in the incidence of translocation was observed in the ${ }^{252} \mathrm{Cf}$ neutrons exposure at a dose rate of $0.02 \mathrm{cGy} / \mathrm{min}$. These results suggest that the formation of dicentrics and translocations differed with source of radiation and dose rate.

Keywords : ${ }^{252} \mathrm{Cf}$ neutrons, dose rate effect, FISH, translocations, low dose rate, biodosimetry, bone marrow, chromosome aberrations.

Introduction

The neutron biology has received wide attention ever since the detonation of A-bomb at Hiroshima. The nuclear incidence at Tokai Mura in the recent past also reemphasized the need for effective dosimetric evaluation of neutron exposure. Apart from atomic bomb survivors and workers of nuclear power plant accidents, most people are exposed to very small doses of neutrons incidentally, medically or occupationally. Hence, there is a need for greater understanding of neutron exposure and its risk assessment. Therefore, the study of the relative biological effectiveness (RBE) of neutrons at various dose rates is important for the risk assessment of occupationally exposed nuclear plant workers and for the estimation of appropriate radiation quantities for neutron therapy.

The atomic bomb radiation in Hiroshima and Nagasaki contained low-energy neutrons (US-JAPAN, 1987). Previous reports have shown that low doses of fission-spectrum neutrons delivered at low dose rates enhanced the neoplastic transformation of mouse C3H10T1/2 cells and 6-thioguanine resistant (6-TG') mutations of mouse L5178Y cells (Hill et al.,1982; Miller et al., 1988; Nakamura \& Sawada 1988). Also, the variations in RBE at different neutron energies and dose rates are of interest in understanding the basic mechanisms of radiation biology (Tanaka et al., 1999). It is important to assess the biological effects of californium ${ }^{252} \mathrm{Cf}$ neutrons, both for medical applications and in order to estimate the effects of exposure to neutrons in atomic bomb radiation.

Radiation-induced dicentrics and ring chromosomes in human lymphocytes are a suitable index for assessing cell damage, but the abnormalities are eliminated immediately after exposure. In contrast to scoring dicentrics and rings, translocations can persist for a longer time and would thus seem to be a more useful biological dosimetric index. Persistent, long-term translocation in bone marrow cells may play a role in the higher incidence of leukemia among survivors of the atomic bomb at Hiroshima (Nakanishi et al., 1999). The numbers of dicentric chromosomes and translocations are thought to be equal just after exposure. However, the ratio of translocations to dicentric chromosomes after neutron irradiation has not yet been clarified. Then the incidence of translocation can be estimated by observing the dicentric chromosome yield without precise examination. Fluorescence in situ hybridization (FISH) is a suitable method for evaluating the ratio of the translocation yields to the dicentric chromosome yields. Nonetheless, there have been few detailed studies on the effects of ${ }^{252} \mathrm{Cf}$ neutrons. In the present study, we 
therefore analyzed the RBE of ${ }^{252} \mathrm{Cf}$ neutrons at different dose rates of exposure in human lymphocytes and bone marrow chromosomes using conventional Giemsa staining and the FISH method.

\section{Materials and Methods}

Radiation source

$A{ }^{252} \mathrm{Cf}$ source, which was installed in a linear accelerator facility at the Research Institute for Radiation Biology and Medicine, Hiroshima University, was used for this study. The ${ }^{252} \mathrm{Cf}$ beam and irradiation system have been described previously (Hoshi et al., 1988). Neutron and Y ray doses were measured by the twin-chamber method. Chambers of IC-17 and IC-17G (Far West Technology Inc., Goleta, CA., USA) were used. The twin chambers were calibrated against the tertiary standard dosimeter (Japanese Association of Radiological Physicists [JARP] dosimeters) using a ${ }^{60} \mathrm{Co} \mathrm{Y}$ ray field. The ${ }^{252} \mathrm{Cf}$ radiation consists of $33 \%$ y rays and $67 \%$ fission neutrons (Hoshi et al., 1988). The distances between the samples and ${ }^{252} \mathrm{Cf}$ radiation source for the exposure at the three dose rates of 2, 0.2 and 0.02 cGy/min were $8 \mathrm{~cm}, 33 \mathrm{~cm}$ and $74.9 \mathrm{~cm}$, respectively. Irradiation of ${ }^{60} \mathrm{Co} \mathrm{y}$-ray at the dose rate of $2 \mathrm{cGy} / \mathrm{min},{ }^{137} \mathrm{Cs}$ Y ray with $0.2 \mathrm{cGy} / \mathrm{min}$ and $0.02 \mathrm{cGy} / \mathrm{min}$ were used as a standard radiation source to estimate the exact $R B E$ value of ${ }^{252} \mathrm{Cf}$ neutrons. The biological effects of ${ }^{137} \mathrm{Cs} \mathrm{Y}$ rays and ${ }^{60} \mathrm{Co} Y$ rays are reported to be the same (Doggett et al., 1983).

\section{Culture methods}

Lymphocytes: The samples for the three dose rates (2, 0.2 and $0.02 \mathrm{cGy} / \mathrm{min} ; 200,20$ and 2 $\mathrm{mGy} / \mathrm{min}$ ) consisted of peripheral blood from 5 healthy adult donors (3 males and 2 females). Lymphocytes were separated using Ficoll-Hypaque centrifuge. $0.5 \times 10^{7}$ cells from isolated lymphocytes were exposed to three radiation sources in a $15 \mathrm{ml}$ conical tube at $37^{\circ} \mathrm{C}$. For long-term (up to $100 \mathrm{~h}$ ) exposure at $37^{\circ} \mathrm{C}$, the viability of lymphocytes was checked by phytohemagglutinin (PHA)-stimulation at $24 \mathrm{~h}$ intervals, using chromosome aberration as an index. The chromosome aberration rate remained stable till $80 \mathrm{~h}$ of exposure without PHA stimulation, and then declined slightly, indicating that the lymphocytes became nonviable after $80 \mathrm{~h}$ of exposure. After the exposure, the whole blood was washed three times with RPMI 1640 medium and cultured for 48 to $50 \mathrm{~h}$ in RPMI 1640 medium containing $0.2 \mu \mathrm{g} / \mathrm{ml}$ PHA. The cultures were arrested with $0.02 \mu \mathrm{g} / \mathrm{ml}$ colcemid at last $1 \mathrm{~h}$, and metaphases were stained with Giemsa solution. Unstable chromosome aberrations such as dicentrics, centric rings, acentric rings, fragments and minute chromosomes were scored. We analyzed the cell cycle in lymphocyte culture using fluorescent plus Giemsa (FPG) method (Perry \& Wolff, 1974) to identify first mitosis. After exposure to different radiation doses of ${ }^{252} \mathrm{Cf}$ neutrons, ${ }^{60} \mathrm{Co}$ y-rays, and ${ }^{137} \mathrm{Cs}$ y-rays, the cells were cultured for $72 \mathrm{hrs}$. Bromodeoxyuridine (BrdU) $(5 \mu \mathrm{g} / \mathrm{ml})$ was added and cultured for $24 \mathrm{~h}$ and harvest at $50 \mathrm{~h}$. Chromosome slides were stained with 33258 Hoechst and exposed to UV, and stained with Giemsa.

Bone marrow cells: For the testing of a single dose rate (2 cGy/min each) from two irradiation sources, ${ }^{252} \mathrm{Cf}$ neutrons and ${ }^{60} \mathrm{Co} \mathrm{y}$ ray, samples consisted of bone marrow cells from 19 donors (11 males and 8 females) who had no hematological malignancies. From each sample $2 \times 10^{7}$ mononuclear cells were separated by Ficoll-Hypaque centrifuge. The separated mononuclear cells were added to RPMI medium contained $20 \%$ of fetal calf serum in $50 \mathrm{ml}$ culture flask and were exposed directly to the radiation source in each experimental series at $37^{\circ} \mathrm{C}$. After the exposure, the cells were cultured for $48 \mathrm{~h}$ with fresh medium and arrested at $47 \mathrm{~h}$ by colcemid administration at the rate of $0.02 \mu \mathrm{g} / \mathrm{ml}$. Unstable chromosome aberrations and chromatid- type aberrations, such as chromatid and chromosome breaks, chromatid and chromosome gaps and chromatid exchanges, were scored. Metaphase spreads were obtained after hypotonic treatment $(0.075 \mathrm{M} \mathrm{KCl})$ with methanol/acetic acid $(3: 1 \mathrm{v} / \mathrm{v})$.

Metaphase fluorescence in situ hybridization (FISH) method of chromosome subsets

Peripheral blood from two healthy adults was used for the metaphase FISH method. Chromosome-specific library DNA probes directly labeled with fluorochromes, termed whole chromosome painting (WCP)-probes, were used for the present study (Vysis; Naperville, IL, USA). WCP-probes for chromosomes 1, 2, and 4 were conjugated to a rhodamine derivative (Spectrum orange; red fluorescence). Whole WCP-probes for chromosomes 6,7 and 9 were conjugated to a fluorescein-isothiocyanate (FITC) derivative (Spectrum green; green fluorescence). These two kinds of probes were mixed and hybridized. Chromosome painting was carried out as described previously (Tanaka et al., 1996). WCP probe DNA was resuspended in the hybridization 
mixture. Slides were washed three times in $2 \times$ SSC followed by short wash under tap water. All slides were mounted in antifade (Oncor, Gaithersburg, MD, USA). Slides with green and red fluorescent probes were counterstained with 0.2 $\mathrm{mg} / \mathrm{ml} 4$ ' 6-diamidino-2 phenylindole dihydrocloride (DAPI).

Dicentric chromosomes were identified by observation of the same metaphase stained by DAPI. The 63 to 352 metaphases were scored in each exposure dose. Type of painted chromosome aberrations was tried to classify according to the Protocol for Aberration Identification and Nomenclature Terminology (PAINT) (Tucker et al., 1995).

\section{Results}

Yields of chromosome aberration, RBE and dose rate effects in lymphocytes

The chromosome aberration frequencies in lymphocytes after exposure to ${ }^{252} \mathrm{Cf}$ neutrons at each of the three dose rates are shown in Table 1. For each dose, 93 to 1,103 metaphases were scored. The dose-response relationships for dicentrics per cell following exposure to ${ }^{252} \mathrm{Cf}$ neutrons, ${ }^{60} \mathrm{Co} \mathrm{y}$-rays and ${ }^{137} \mathrm{Csy}$-rays at the dose rates of 2, 0.2 , and $0.02 \mathrm{cGy} / \mathrm{min}$ are shown in Fig. 1. Linear models and linear quadratic models were plotted to show the relationship between chromosome aberration frequencies and the radiation dose exposure of ${ }^{252} \mathrm{Cf}$ neutrons, and each of ${ }^{60} \mathrm{Co} \mathrm{Y}$ - and ${ }^{137} \mathrm{Cs} \mathrm{Y}$ rays, respectively. Direct exposure to ${ }^{252} \mathrm{Cf}$ neutrons contains $33 \%$ of
Y ray component (Hoshi et al., 1988). Subtracted $Y$ ray component of $252 \mathrm{Cf}$ neutrons and direct 252 Cf neutrons containing a $Y$ ray component were designated $\mathrm{Cf}(\mathrm{n})$ and $\mathrm{Cf}$. The values of the linear model were $Y=-0.037+0.369 \mathrm{D}$ in $\mathrm{Cf}$ and $\mathrm{Y}=$ $-0.051+0.581 \mathrm{D}$ in $\mathrm{Cf}(\mathrm{n})$ at $2 \mathrm{cGy} / \mathrm{min}$. The value of the linear quadratic model was $Y=7.098 \times 10^{-3}+$ $5.906 \times 10^{-2} \mathrm{D}+2.358 \times 10^{-2} \mathrm{D}^{2}$ in the ${ }^{60} \mathrm{Co} \mathrm{Y}$ rays $(\mathrm{Y}$ : dicentric chromosome aberration yield per each cell; D: radiation dose in Gy ) .

The dose-response relationship for the radiation dose of $0.2 \mathrm{cGy} / \mathrm{min}$ and $0.02 \mathrm{cGy} / \mathrm{min}$ for the ${ }^{252} \mathrm{Cf}$ neutrons was $Y=-0.044+0.3 \mathrm{D}$ in $\mathrm{Cf}$ and $\mathrm{Y}=$ $0.044+0.464 \mathrm{D}$ in $\mathrm{Cf}(\mathrm{n})$ at $0.2 \mathrm{cGy} / \mathrm{min}$, and $\mathrm{Y}=$ $-0.016+0.364 \mathrm{D}$ in $\mathrm{Cf}$ and $\mathrm{Y}=-0.015+0.561 \mathrm{D}$ in $\mathrm{Cf}(\mathrm{n})$ at $0.02 \mathrm{cGy} / \mathrm{min}$, respectively, as established using a linear model. Dicentric yields in ${ }^{252} \mathrm{Cf}$ neutrons at the three dose rates of 2, 0.2 and 0.02 $\mathrm{cGy} / \mathrm{min}$ were similar, which shows that there was no dose rate effect among these radiation dose rates. In covariance analysis, the differences between dicentric yields were not statistically significant $(\mathrm{p}>0.5)$. The dose-response relationships of the two dose rates for the ${ }^{137} \mathrm{Cs} \mathrm{Y}$ rays are also shown in Fig. 1 , where $Y=9.87 \times 10^{-3}$ $+4.364 \times 10^{-2} \mathrm{D}$ at $0.2 \mathrm{cGy} / \mathrm{min}$ and $\mathrm{Y}=-0.0134+$ $0.0472 \mathrm{D}$ at $0.02 \mathrm{cGy} / \mathrm{min}$, respectively. The dose-response relationships for the formation of

Table 1. Yield of chromosome aberrations after exposures to ${ }^{252} \mathrm{Cf}$ neutrons at the dose rates of 2 cGy/min, 0.2

\begin{tabular}{|c|c|c|c|c|c|c|c|c|c|}
\hline \multicolumn{10}{|c|}{ cGy/min and 0.02 cGy/min } \\
\hline $\begin{array}{c}\text { Dose rate of } \\
{ }^{252} \mathrm{Cf} \\
\text { neutrons }\end{array}$ & \multicolumn{2}{|c|}{$\begin{array}{l}\text { Exposure dose } \\
\text { (dose of Cf(n) } \\
\text { (Gy) }\end{array}$} & $\begin{array}{l}\text { Obs. } \\
\text { cells }\end{array}$ & Dic & Rc & $\begin{array}{c}\text { Dic } \\
\text { per cell }\end{array}$ & $\begin{array}{l}\text { Dic+Rc } \\
\text { per cell }\end{array}$ & $\begin{array}{c}\text { Ace }+F g \\
\text { per cell }\end{array}$ & $\begin{array}{c}\text { Min } \\
\text { per cell }\end{array}$ \\
\hline \multirow{9}{*}{2} & 0 & & 4,000 & 2 & 0 & 0.0005 & 0.0005 & 0.0015 & 0.0015 \\
\hline & 0.05 & $(0.03)$ & 840 & 12 & 12 & 0.014 & 0.028 & 0.008 & 0.034 \\
\hline & 0.1 & $(0.07)$ & 591 & 21 & 35 & 0.037 & 0.095 & 0.042 & 0.054 \\
\hline & 0.2 & $(0.16)$ & 1,103 & 65 & 60 & 0.07 & 0.104 & 0.045 & 0.082 \\
\hline & 0.5 & $(0.32)$ & 1,016 & 124 & 116 & 0.122 & 0.236 & 0.065 & 0.137 \\
\hline & 1.0 & $(0.65)$ & 526 & 147 & 130 & 0.279 & 0.469 & 0.137 & 0.245 \\
\hline & 1.5 & $(0.97)$ & 310 & 145 & 122 & 0.47 & 0.861 & 0.258 & 0.448 \\
\hline & 2.0 & (1.29) & 200 & 131 & 130 & 0.66 & 1.305 & 0.46 & 0.815 \\
\hline & 2.5 & (1.62) & 200 & 201 & 180 & 1.01 & 1905 & 0.61 & 0.85 \\
\hline \multirow{4}{*}{0.2} & 0.5 & $(0.32)$ & 484 & 113 & 41 & 0.233 & 0.318 & 0.089 & 0.215 \\
\hline & 1.0 & (0.65) & 596 & 198 & 119 & 0.332 & 0.532 & 0.223 & 0.364 \\
\hline & 2.0 & (1.29) & 93 & 64 & 22 & 0.688 & 0.925 & 0.323 & 0.484 \\
\hline & 3.0 & (1.94) & 125 & 114 & 68 & 0.912 & 1.456 & 0.584 & 0.944 \\
\hline \multirow{4}{*}{0.02} & 0.25 & $(0.16)$ & 883 & 56 & 19 & 0.063 & 0.085 & 0.059 & 0.082 \\
\hline & 0.5 & $(0.32)$ & 600 & 77 & 13 & 0.128 & 0.150 & 0.087 & 0.098 \\
\hline & 0.75 & $(0.49)$ & 600 & 172 & 27 & 0.287 & 0.332 & 0.233 & 0.250 \\
\hline & 0.85 & $(0.55)$ & 600 & 176 & 69 & 0.293 & 0.408 & 0.245 & 0.338 \\
\hline
\end{tabular}

Obs.: Observed, Dic: Dicentric chromosome, Rc: Centric ring, Ace: Acentric ring, Fg: Fragment, Min: Mintute 
acentric rings and minute chromosomes per cell at the three dose rates of ${ }^{252} \mathrm{Cf}$ neutrons were similar. type were directly proportional to the exposure dose, which reached the saturation phase at above

Fig. 1. Dose-response relationship of ${ }^{252} \mathrm{Cf}$ neutron $(\mathrm{Cf})$ and ${ }^{60} \mathrm{Co}$ rray and ${ }^{137} \mathrm{Cs}$ rray in human lymphocytes chromosomes at the three dose rates (2 cGy/min, $0.2 \mathrm{cGy} / \mathrm{min}$ and $0.02 \mathrm{cGy} / \mathrm{min})$. Recalculated data [Cf(n)] are also shown in this figure. Yields of dicentrics per cell were used for the present analysis.

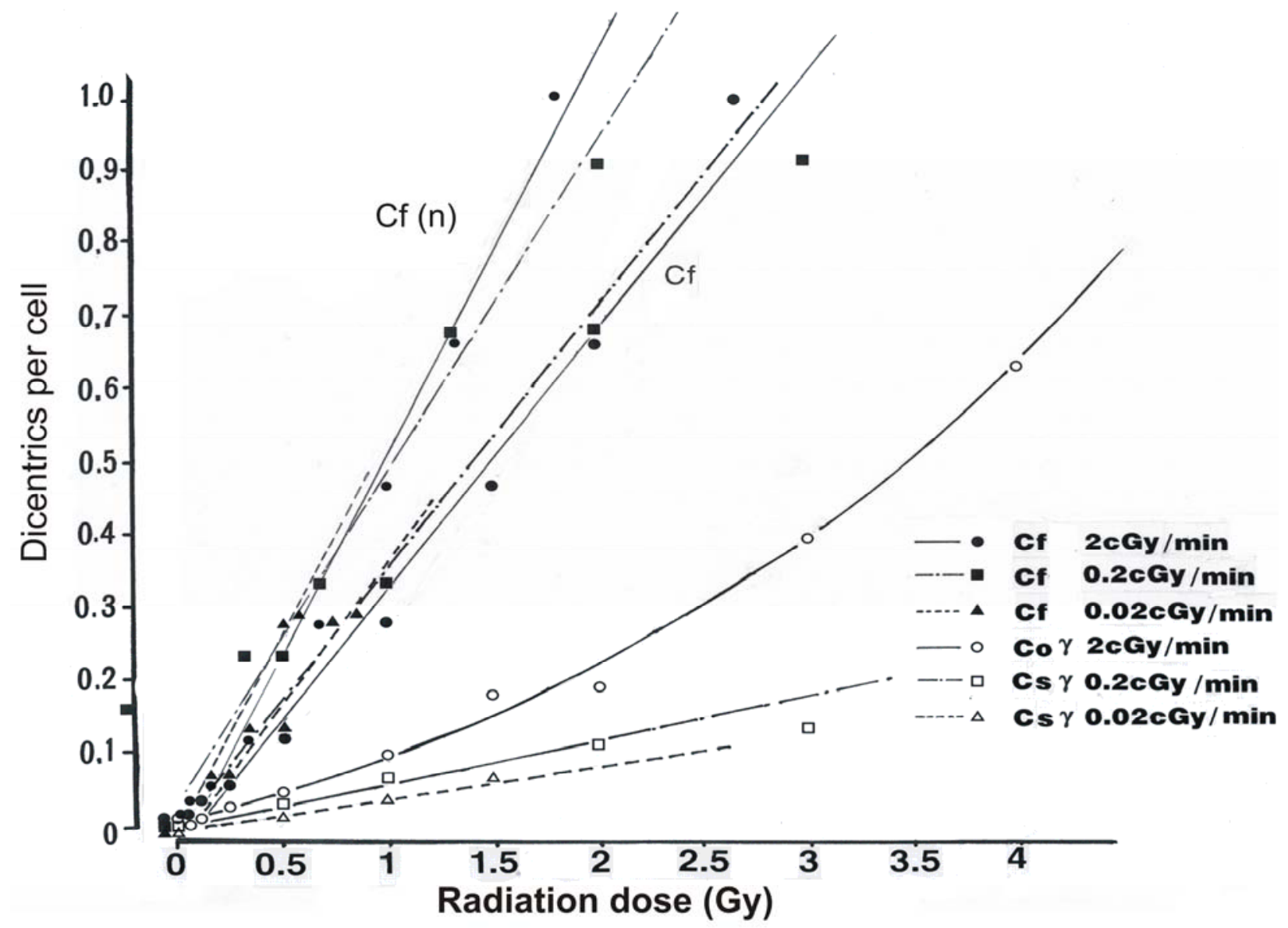

RBE values were calculated according to the formula: RBE of $\mathrm{Cf}(\mathrm{n})=$ 〔RBE of $\mathrm{Cf}-\mathrm{Cf}(\mathrm{Y})$ )

$/ \mathrm{Cf}(\mathrm{Y}) ; \mathrm{Cf}(\mathrm{Y}): \mathrm{Y}$ component of $\mathrm{Cf}, \mathrm{Cf}(\mathrm{n})$ : neutron components of $\mathrm{Cf}$ neutrons. The RBE values of $\mathrm{Cf}$ and $\mathrm{Cf}(\mathrm{n})$ in the lymphocytes were 2.14 and 3.24 at an aberration yield equivalent to 2 Gy, and 2.45 and 3.63 at an aberration yield equivalent to 0.5 cGy. The RBE values at the three dose rates of 2 , 0.2 and 0.02 cGy $/ \mathrm{min}$ at an aberration yield equivalent to 1 Gy were 2.3, 7.6 and 7.7 for $\mathrm{Cf}$, and $3.3,11.0$ and 12.0 for $\mathrm{Cf}(\mathrm{n})$, respectively.

Yields of chromosome aberrations and RBE in bone marrow cells

The dose-response relationships in bone marrow cells at the dose rate of $2 \mathrm{cGy} / \mathrm{min}$ are shown in Table 2 \& Fig. 2. Chromosome aberration yields of dicentrics plus centric rings and chromatid
$1 \mathrm{~Gy}$. In the case of ${ }^{252} \mathrm{Cf}$ neutrons, a linear model was plotted to show the relationship between the radiation dose and aberration yields in the bone marrow cells, with respect to the initial slope at low doses of less than 0.6 Gy. The dose-response relationship of $\mathrm{Cf}(\mathrm{n})$ was $\mathrm{Y}=7.89+64.2 \mathrm{D}$ for the chromatid type aberrations, $Y=1.71+69.6 \mathrm{D}$ and $Y=-0.26+69.6 D$ for chromosome type and the dicentrics plus centric rings, respectively $(\mathrm{Y}$ : chromosome aberration yield; $D$ : radiation dose in $\mathrm{Gy})$. The RBE values of $\mathrm{Cf}(\mathrm{n})$ with respect to ${ }^{60} \mathrm{Co}$ $\checkmark$ rays were 6.5 for the chromatid type, 4.4 for the chromosome type and 10.6 for dicentrics plus rings. These RBE values were higher than those obtained in lymphocytes.

Detection of translocation by the FISH

The frequency of translocations detected by 
Table 2. Frequencies of chromosome type- and chromatid type- aberrations in human bone marrow cells, irradiated by ${ }^{252}$ Cf neutron and ${ }^{60} \mathrm{CoV}$-rays.

\begin{tabular}{|c|c|c|c|c|c|c|c|c|}
\hline $\begin{array}{l}{ }^{252} \mathrm{Cf} \\
\text { neutron } \\
\text { Dose(Gy) }\end{array}$ & $\begin{array}{l}\text { Obs. } \\
\text { cells }\end{array}$ & $\begin{array}{l}\text { Cells(\%) } \\
\text { with chr. } \\
\text { ab. }\end{array}$ & Dic & Rc & $\begin{array}{l}\text { Cells with } \\
\text { Dic+Rc (\%) }\end{array}$ & ace & $\mathrm{Fg}$ & $\begin{array}{l}\text { Cells with } \\
\text { chromatid } \\
\text { ab. (\%) }\end{array}$ \\
\hline $\begin{array}{ll}0 & (0)^{*}\end{array}$ & 492 & $\begin{array}{ll}3 & (0.5)\end{array}$ & 0 & 1 & $1(0.2)$ & 0 & 0 & $40(8.1)$ \\
\hline $0.1(0.06)^{*}$ & 181 & $9 \quad(5.0)$ & 0 & 6 & $6(3.3)$ & 3 & 0 & $21(11.6)$ \\
\hline $0.2(0.13)^{*}$ & 585 & $76(13.0)$ & 22 & 36 & $54(9.2)$ & 23 & 6 & 96 (16.4) \\
\hline $0.4(0.26)^{*}$ & 400 & $44(11.0)$ & 19 & 17 & $33(9.0)$ & 13 & 1 & $86(21.5)$ \\
\hline $0.8(0.52)^{*}$ & 372 & $84(22.6)$ & 25 & 35 & $55(14.8)$ & 35 & 0 & $102(27.4)$ \\
\hline $1.2(0.78)^{*}$ & 130 & $26(20.0)$ & 4 & 16 & $21(16.2)$ & 13 & 0 & $52(40.0)$ \\
\hline \multicolumn{9}{|l|}{$\begin{array}{l}{ }^{60} \mathrm{Coy} \\
\text { Dose(Gy) }\end{array}$} \\
\hline 0 & 399 & $\begin{array}{ll}4 & (1.0) \\
\end{array}$ & 0 & 1 & $\begin{array}{ll}1 & (0.3) \\
\end{array}$ & 3 & 0 & $\begin{array}{ll}26 & (6.5) \\
\end{array}$ \\
\hline 0.25 & 298 & $17(5.7)$ & 7 & 7 & $13(4.4)$ & 4 & 0 & $32(11.9)$ \\
\hline 0.5 & 488 & $40(8.2)$ & 12 & 18 & $17(5.1)$ & 13 & 0 & 65 (13.3) \\
\hline 1 & 364 & $65(17.9)$ & 11 & 26 & $37(10.1)$ & 30 & 3 & $84(23.1)$ \\
\hline 1.5 & 82 & 15 (18.2) & 3 & 8 & $11(13.4)$ & 6 & 0 & $38(46.3)$ \\
\hline 2 & 236 & $53(22.4)$ & 17 & 20 & $32(13.6)$ & 30 & 0 & 73 (36.7) \\
\hline
\end{tabular}

metaphase FISH was established for ${ }^{60} \mathrm{Coy}$ rays and ${ }^{252} \mathrm{Cf}$ neutrons at the dose rates of $2 \mathrm{cGy} / \mathrm{min}$ and $0.02 \mathrm{cGy} / \mathrm{min}$. In this experiment, chromosomes 1 , 2 and 4 were stained red using the WCP1, 2, and 4 probes and chromosomes 6 , 7 and 9 were stained green using the WCP 6,7 , and 9 probes. A representative painted metaphase is shown in Fig. 3a. The dicentric chromosome was scored in the DAPI-stained metaphase (Fig. 3b). The dose-response relationships between observed and calculated translocation yields and observed dicentric chromosome yields are summarized in Table 3 . The ratios of translocation to dicentric chromosome yields for ${ }^{60} \mathrm{Co} \mathrm{Y}$ rays and ${ }^{252} \mathrm{Cf}$ neutrons were obtained in two ways. One was the ratio of observed translocations and observed dicentric chromosomes within 6 painted pairs of chromosomes by metaphase
FISH (6-9th column in Table 3). The second was the ratio of calculated translocation frequencies based on the FISH results and the observed Fig. 2. Dose-response relationship of chromosome aberration rate and radiation doses of bone marrow chromosomes at the dose rate of 2 cGy/ min. Observed values [Cf(n)] were recalculated by subtraction of yray contamination. Yields of chromatid type aberration, chromosome aberration and dicentric plus rings were used for present analysis.
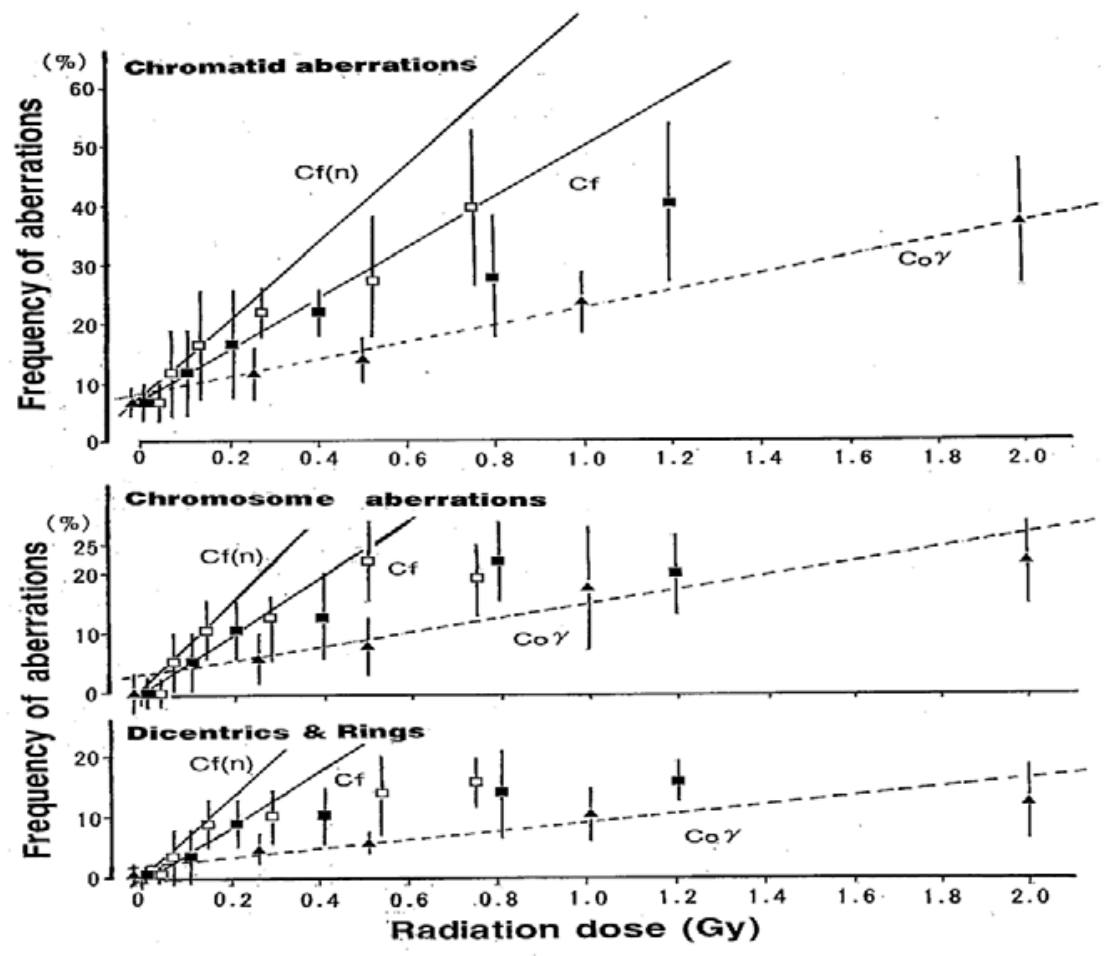

"RBE of ${ }^{252} \mathrm{Cf}$ neutrons"

by Tanaka et al. Indian J.Sci.Technol. 
Table 3. Detection of translocations induced by ${ }^{252} \mathrm{Cf}$ neutrons, ${ }^{60} \mathrm{Co} y$-rays, and ${ }^{137} \mathrm{Cs}$ y-rays with two dose rates of 2 cGy/min and 0.02 cGy/min by metaphase FISH using 6 pairs of chromosomes (chromosomes 1, 2 and 4 in red color and chromosomes 6,7 and 9 in green color). Number of chromosome aberrations is listed.

\begin{tabular}{|c|c|c|c|c|c|c|c|c|c|c|}
\hline \multirow[b]{2}{*}{ Radiation } & \multirow[b]{2}{*}{$\begin{array}{l}\text { Radia } \\
\text { tion } \\
\text { dose } \\
\text { (Gy) }\end{array}$} & \multirow[b]{2}{*}{$\begin{array}{l}\text { No. } \\
\text { of obs. } \\
\text { cells }\end{array}$} & \multicolumn{2}{|c|}{$\begin{array}{c}\text { No. of abnormal } \\
\text { cells }\end{array}$} & \multicolumn{4}{|c|}{$\begin{array}{l}\text { No. of painted abnormal chromosomes } \\
\text { detected by FISH }\end{array}$} & \multicolumn{2}{|c|}{$\begin{array}{l}\text { No. of calculated } \\
\text { chromosomes }\end{array}$} \\
\hline & & & Cu cells & Cs cells & $\begin{array}{l}\text { Dicent } \\
\text { rics }\end{array}$ & \begin{tabular}{|l|} 
Translo \\
cation
\end{tabular} & \begin{tabular}{|c|} 
Translo \\
cation \\
/dicentrics \\
in painted 6 \\
chromosom \\
es
\end{tabular} & $\begin{array}{c}\text { Translo } \\
\text { cations } \\
\text { per cells }\end{array}$ & $\begin{array}{c}\text { Translo } \\
\text { cations } \\
\text { in all } \\
\text { genome }\end{array}$ & $\begin{array}{c}\text { Translo } \\
\text { cation } \\
\text { / dicentrics } \\
\text { in all } \\
\text { genome }^{c}\end{array}$ \\
\hline \multirow{4}{*}{$\begin{array}{l}{ }^{252} \mathrm{Cf} \\
\text { neutrons } \\
\text { (2 cGy/min) }\end{array}$} & 0 & 352 & 0 & 3 & $0(0)^{\mathrm{a}}$ & $2(2)$ & 0 & 0.0057 & 0.0104 & 08 \\
\hline & 0.5 & 129 & 66 & 10 & $24(18)$ & $14(10)$ & 0.58 & 0.1085 & 0.1982 & 1.624 \\
\hline & 1 & 270 & 100 & 29 & $25(23)$ & $35(26)$ & 1.4 & 0.1296 & 0.2367 & 0.848 \\
\hline & 1.5 & 191 & 79 & 23 & $27(25)$ & $41(23)$ & 1.52 & 0.2147 & 0.3921 & 0.83 \\
\hline \multirow{4}{*}{$\mid \begin{array}{l}{ }^{252} \mathrm{Cf} \text { neutrons } \\
(0.02 \text { cGy/min })\end{array}$} & 0.25 & 100 & 13 & 17 & 2(2) & $25(17)$ & 12.5 & 0.25 & 0.4568 & 7.25 \\
\hline & 0.5 & 100 & 33 & 18 & 12(12) & $37(18)$ & 3.08 & 0.37 & 0.6758 & 5.28 \\
\hline & 0.75 & 100 & 20 & 13 & $13(13)$ & $21(13)$ & 1.6 & 0.21 & 0.3835 & 1.34 \\
\hline & 0.85 & 102 & 37 & 14 & $21(19)$ & $27(14)$ & 1.28 & 0.265 & 0.484 & 1.65 \\
\hline \multirow{5}{*}{$\begin{array}{l}{ }^{60} \mathrm{Co} \text { Y-rays } \\
(2 \mathrm{cGy} / \mathrm{min})\end{array}$} & 0 & 352 & 0 & 3 & $0(0)$ & $2(2)$ & 0 & 0.0057 & 0.0104 & \\
\hline & 1 & 63 & 24 & 10 & $4(4)$ & $13(10)$ & 3.25 & 0.206 & 0.3762 & $\begin{array}{r}0.8 \\
2.13\end{array}$ \\
\hline & 2 & 120 & 32 & 23 & $9(7)$ & $37(23)$ & 4.11 & 0.308 & 0.5625 & 2.93 \\
\hline & 3 & 151 & 61 & 44 & 29(14) & 78(44) & 2.69 & 0.516 & 0.9423 & 2.39 \\
\hline & 4 & 86 & 43 & 23 & $10(9)$ & $39(23)$ & 3.9 & 0.453 & 0.8273 & 1.32 \\
\hline \multirow{3}{*}{$\begin{array}{l}{ }^{137} \text { Cs y-rays } \\
\text { (0.02 cGy/min) }\end{array}$} & 0.75 & 200 & 4 & 7 & $1(1)$ & $11(7)$ & 11.0 & 0.055 & 0.1004 & 8.30 \\
\hline & 0.85 & 178 & 1 & 5 & $1(1)$ & $7(5)$ & 7.0 & 0.039 & 0.0713 & 2.67 \\
\hline & 1 & 122 & 4 & 6 & 1(1) & $10(6)$ & 10 & 0.082 & 0.1498 & 4.13 \\
\hline
\end{tabular}

${ }^{a}$ : Numbers in parenthesis are the numbers of observed cells. ${ }^{b}:$ The expected number of translocations for the whole

genome was calculated using Lucas's formula. c: Dicentric chromosome detected by conventional Giemsa staining were used for analysis. Dicentrics: dicentric chromosome. Ratios of translocation to dicentrics yields obtained in two ways, in different radiation doses are shown in bold letters.

dicentric chromosomes by conventional Giemsa staining (10-11th column in Table 3). In the analysis, chromosome samples obtained from the same experiment were analyzed by both the methods- FISH and conventional Giemsa staining. We obtained the expected translocation rates from observed translocation rates using Lucas's formula (Lucas et al., 1993): Frg $=2.05$ $f r(1-f r)+f g(1-f g)-f r f g) ~ F g$, where $f r$ and $f g$ are the percentages of the genome stained in red and green, respectively. The DNA contents of the 6 chromosomes cover $38.2 \%$ of the whole human genome. The DNA contents obtained by Morton were used for the calculation (Morton, 1991). Frg and Fg indicate the observed and expected translocation frequencies, respectively. The number of painted chromosome aberrations found in cells with stable-type chromosome aberrations (Cs cells) was used for evaluating calculated translocations. Translocations found in the cells with unstable-type aberrations, such as dicentrics and ring chromosomes (Cu cells), were excluded from the present analysis. Frequencies of observed and calculated translocations and dicentric chromosomes are listed in Table 3. The
Fig. 3. (a) Representative painted metaphase by FISH, which has translocation between chromosomes 1 and 7. Star shows abnormal chromosomes. (b) DAPl-stained metaphase with dicentric chromosomes. Star shows dicentric chromosome.
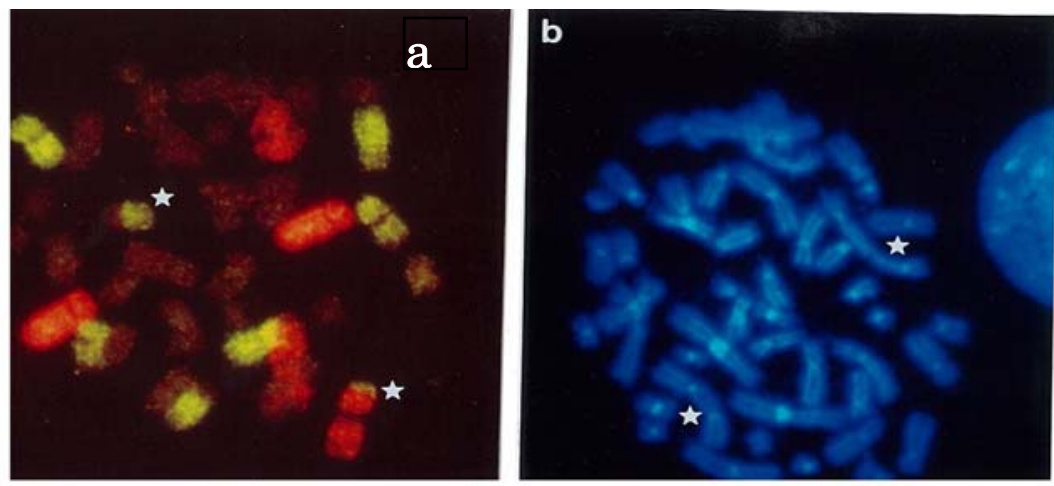
Fig. 4. Ratio of translocation and dicentric yields at two dose rates (2 cGy/min and 0,02cGy/min) of ${ }^{252}$ Cf neutrons, ${ }^{60}$ Co yray and ${ }^{137} \mathrm{Cs} y$ ray exposures in human lymphocytes. Translocation was calculated from observed FISH results. Dicentric chromosome is observed in conventional Giemsa staining. Closed and open circles show the value of ratio in the different exposure dose of ${ }^{252}$ Cf neutrons and yray $\left({ }^{60}\right.$ Coyray and ${ }^{137}$ Csyray) exposures,

respectively. The number beside closed ( $\bullet$ ) and open ( $\circ$ kircles indicates exposure dose in each radiation source. Solid and dotted lines indicate mean values of ${ }^{252} \mathrm{Cf}$ neutrons and yray ${ }^{60}$ Coyray and ${ }^{137} \mathrm{Csy}$ ray) at the dose rate of $2 c G y / m i n$ and $0.02 c G y / m i n$, respectively. Mean value was obtained from ratio of translocation to dicentrics in each radiation dose.

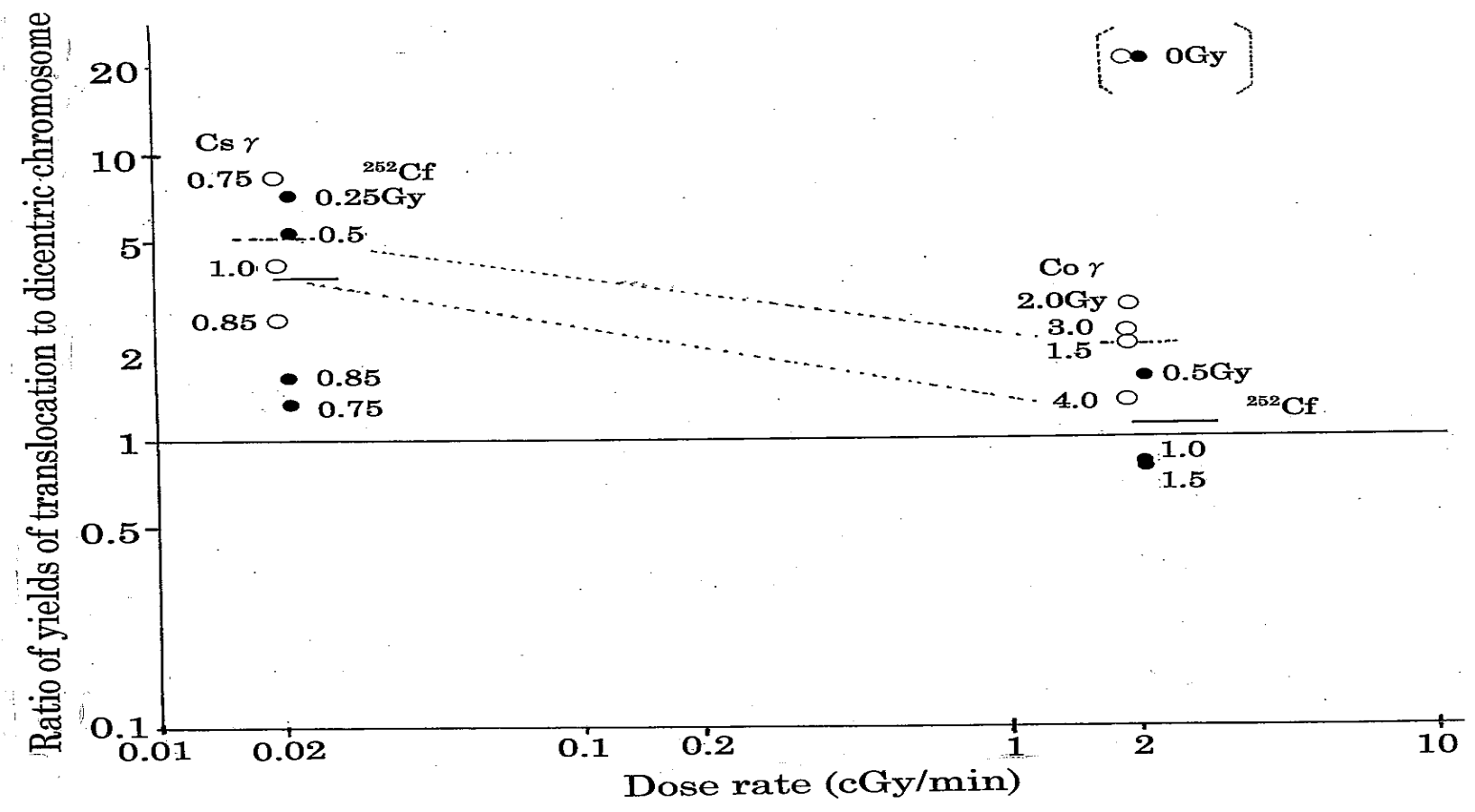

ratios of observed translocation to dicentric chromosomes were $0.58-1.52$ for ${ }^{252} \mathrm{Cf}$ neutrons exposure at a dose rate of $2 \mathrm{cGy} / \mathrm{min}$, which have a mean incidence of dicentric chromosome observed higher than that of translocations at low dose of 0.5 Gy (8th column in Table 3 ). On the other hand, the ratios were 2.7 to 4.1 for ${ }^{60} \mathrm{Co} \mathrm{Y}$ ray exposure at the dose rate of $2 \mathrm{cGy} / \mathrm{min}$. In contrast, the ${ }^{252} \mathrm{Cf}$ neutrons experiment at the dose rate of $0.02 \mathrm{cGy} / \mathrm{min}$, the yields of translocations were significantly different from those exposed at the dose rate of $2 \mathrm{cGy} / \mathrm{min}$, although the number of dicentric chromosomes was not significantly different from that of $2 \mathrm{cGy} / \mathrm{min}$. The ratios of calculated translocation to dicentric chromosome were 1.3-2.9 at the dose rate of $2 \mathrm{cGy} / \mathrm{min}$ (10th column in Table 3). Similarly, these ratios were 2.6-8.3 in the case of ${ }^{137} \mathrm{Cs} y$ exposure at 0.02 cGy/min, in which the mean translocations observed were higher than dicentric chromosomes. Ratios of dicentric to translocation yields at two dose rates (2 cGy/min and $0,02 \mathrm{cGy} / \mathrm{min}$ ) of ${ }^{252} \mathrm{Cf}$ neutrons and ${ }^{60} \mathrm{Coy}$ ray and ${ }^{137} \mathrm{Csy}$ ray exposures are summarized in Fig.4. Enhancement of translocation frequency was observed at the lower dose rate of $0.02 \mathrm{cGy} / \mathrm{min}$ (Table 3 \& Fig.4). Mean values of ratio of translocation to dicentric chromosome in ${ }^{252} \mathrm{Cf}$ neutrons and $\mathrm{y}$ rays $\left({ }^{60} \mathrm{Coy}\right.$ ray and ${ }^{137} \mathrm{Csy}$ ray) were 2.19 and 1.99 , and 5.03 and 1.3 in two different dose rates (2 cGy/min and $0.02 \mathrm{cGy} / \mathrm{min}$ ), respectively. It means that ${ }^{252} \mathrm{Cf}$ neutrons induced dicentric chromosome 1.3-2.0 times higher than $\mathrm{Y}$ rays $\left({ }^{60} \mathrm{Coy}\right.$ ray and ${ }^{137} \mathrm{Cs} \mathrm{Y}$ ray). The ratio of yield of translocations to dicentric chromosomes was influenced by linear energy transfer (LET) of the radiation, dose rate and the dose in quantity.

\section{Discussion}

There is a paucity of information on the cytogenetic effects of ${ }^{252} \mathrm{Cf}$ neutron radiation in relation to the dose-response and dose rate effects on normal human lymphocytes and bone marrow cells. Lloyd et al. (1978) reported that the dose response curve for ${ }^{252} \mathrm{Cf}$ neutrons at $18 \mathrm{rad} / \mathrm{h}(0.45$ cGy/min) was $Y=0.6 D$ (Y: yields of dicentrics per cell; D: radiation dose in Gy). In this linear-model, a coefficient value was similar to that of the present study.

RBE values of ${ }^{252} \mathrm{Cf}$ neutrons [Cf(n)] at the 
dose rate of $2 \mathrm{cGy} / \mathrm{min}$ with respect to ${ }^{60} \mathrm{Co} \mathrm{y}$ rays were obtained by both chromosome analysis and FISH methods in human lymphocytes and the value was 2.1-24.6, respectively. In earlier trials in this study, the RBE of ${ }^{252} \mathrm{Cf}$ neutron was evaluated using several endpoints. The RBE of ${ }^{252} \mathrm{Cf}$ neutrons with respect to ${ }^{60} \mathrm{Co} \mathrm{y}$ rays was 27 at very low doses of exposure with a dose rate of 0.2 cGy/min, and decreased to 6 with an aberration yield equivalent to 4 Gy (Lloyd et al., 1978), these findings were similar to those obtained here. In the present study, the RBE value of ${ }^{252} \mathrm{Cf}$ neutrons [Cf(n)] was 24.6 at low dose (with aberration yield equivalent to $0.05 \mathrm{~Gy}$ ) and was 7.63 at 0.2 $\mathrm{cGy} / \mathrm{min}$ with an aberration yield equivalent to $1 \mathrm{~Gy}$. The RBE of ${ }^{252} \mathrm{Cf}$ neutrons in human hematopoietic stem cells and fibroblastic stem cells were 1.8-2.7 (Shigeta et al., 1988). Furthermore, other studies have reported that the RBE values of cell killing and $6-\mathrm{TG}^{\mathrm{r}}$ mutation in a human cancer cell line were 2.6, 2.7, respectively, and those of micronucleus formation in human lymphocytes, and of colony formation and 6-TG ${ }^{r}$ mutation in human T-cell lymphocytes were 2.7, 4-5 and 11, respectively (Ban et al .,1987; Ban et al .,1991; Nakamura \& Sawada,1988). These RBE values at the dose rate of $2 \mathrm{cGy} / \mathrm{min}$ examined at the same facility were similar to those of present chromosome analysis. In our study, the RBE value was close to 16.2 in the exposure at low dose with a low dose rate (e.g., at an aberration yield equivalent to 0.1 Gy with a dose rate of 0.02 cGy/min). The International Commission on Radiological Protection (ICRP) recommended that the Quality Factor of neutrons be increased to 20 (ICRP, 1991). Our results further support this recommendation.

RBE values of $\mathrm{Cf}(\mathrm{n})$ in human bone marrow were determined for the first time in the present study, and were 6.5 for chromatid-type and 4.4 for chromosome-type aberrations at the dose rate of 2 $\mathrm{cG} / \mathrm{min}$. These values were higher than those of lymphocytes obtained in the present study. Bone marrow cell mortality is one of the causes of radiation-induced damage. In two previous studies, the $L_{50}$ value for radiation in bone marrow cells was reported to be approximately 3.5 to 4 Gy (Kamada et al., 1989; Fujita et al., 1991).

The reverse dose rate effect was reported first by Hill et al. (1985) as the rates of in vitro oncogenic transformation induced by neutrons in $\mathrm{C} 3 \mathrm{H} 101 / 2$ cells were enhanced by protracting the radiation exposure. In addition, this effect enhanced the mutation frequency in the low dose range (Nakamura \& Akiyama 1988; Kubota et al., 1989). In the present study with ${ }^{252} \mathrm{Cf}$ neutrons, http://www.indjst.org

Vol.2 No 1 (Jan. 2009) which have a mean energy level of $2.3 \mathrm{MeV}$, the enhancement of frequency of translocation was observed at a dose rate of $0.02 \mathrm{cGy} / \mathrm{min}$, was similar to the reverse dose rate effects. However, yields of dicentric chromosome aberration in the lymphocytes did not show any reverse dose rate effect. Cell killing also did not produce this effect in ${ }^{252} \mathrm{Cf}$ neutrons (Nakamura \& Sawada, 1988). But the reverse dose rate effect was not clearly demonstrated in in vivo and in vitro experiments using fresh cells. The enhancement was not observed when using low-LET radiation or neutrons with LETs above $120 \mathrm{keV} / \mu \mathrm{m}$. But it was observed with fission neutrons at dose rates below $1 \mathrm{cGy} / \mathrm{min}$, and it appeared to be more prominent at doses around the 20 cGy range (Kubota et al., 1989). Rossi and Kellerer (1986) and Brenner and Hall (1990) postulated that the reverse dose rate effect might be due to variations of response during the cell cycle. Tauchi et al. (1996) suggested that a radiation-induced G2 block may be partly responsible for the inverse dose rate effect. However, this hypothesis does not explain the absence or small enhancement of reverse dose rate effects in a rays and monoenergetic neutrons (Hieber et al., 1989; Miller et al., 1990).

The irregular behavior of the reverse dose rate effect among different samples and among such indices as cell killing and chromosome aberrations suggests that the effect might not be directly related to the primary radiation DNA damage, but rather might reflect the different sizes of radiation damage target area among these indices. Most such mutations usually result in deletion (Whaley \& Little, 1990). However, our analysis of chromosomal deletions such as those associated with acentric rings and minute chromosomes, showed that these deletions could not elicit the reverse dose rate effect (data not shown). This finding might suggest that submicroscopic deletions make a major contribution to these phenomena.

The dual color FISH method using 6 pairs of chromosome (chromosomes 1, 2, and 4 in red and chromosomes 6,7 and 9 in green) revealed the incidences of translocation and of dicentric chromosomes induced by ${ }^{252} \mathrm{Cf}$ neutrons. Before development of the FISH method, several reports indicated that the ratio of translocations to dicentric chromosome yields was $1: 1$, since the opportunities for these two types of chromosomal aberrations to occur during mitosis were approximately equal (Hansmann et al., 1983). Results on the ratio of translocations to dicentric chromosome formation after exposure to X-rays or 
${ }^{60}$ Coy rays, as analyzed using $\mathrm{FISH}$, have been controversial. Some studies have reported that the ratio was 1:1 (Lucas et al., 1992; Natarajan et al., 1992; Nakano et al., 1993; Straume \& Lucas, 1993; Kovacs et al., 1994; Kanda \& Hayata, 1996), and others that translocations occurred more frequently than dicentric chromosomes (Schmid et al., 1992; Bauchinger et al., 1993; Tucker et al., 1993; Natarajan et al .,1994; Fernandez et al., 1995; Lucas et al., 1996). In the present study, the ratio of translocations to dicentric chromosome yields were 1.3-7.2 and 2.7-8.3 in the exposure of ${ }^{60} \mathrm{Co}$ $\mathrm{Y}$-rays at a dose rate of $2 \mathrm{cGy} / \mathrm{min}$ and ${ }^{137} \mathrm{Cs} \mathrm{Y}$ -rays at a dose rate of $0.02 \mathrm{cGy} / \mathrm{min}$, respectively.

The difference in these results has been attributed at least partially to misscoring of the dicentric chromosomes. Schmid et al. (1992) and others (Nakano et al., 1993; Kanda \& Hayata, 1996) have attempted to use the FISH method and both centromere and whole painting probe detections. Ambiguity on the scoring of translocations by FISH also probably contributed to these discrepancies, particularly in scoring of cells with complex chromosome aberrations (Lucas et al., 1996). Lucas (1998) proposed S-value to understand the radiation signature. Accordingly, the ratio of induced complete translocation to incomplete translocation as seen by FISH can be cytogenetic fingerprint of exposure to radiation of different quality. High LET radiation may have higher chance of producing an incomplete chromosome changes as the densely packed double strand breaks likely to lead in correct and incomplete rejoining. Also high LET radiation produces smaller chromosome pieces compared to low LET radiation (Gajendran, 2007). The small translocation would be scored as a normal metaphase. Present FISH experiment using 6 pairs of chromosome with two different colours subset was very complex for scoring complete or incomplete translocation. Therefore, we ordinary scored the ratio of translocation to dicentrics in different radiation doses. Both translocations and dicentric chromosome yields would be influenced by several conditions, such as LET, dose rate, culture time, first or second mitosis in the cell division, time after drawing blood and chromosomal localization in the cell nucleus. The misrepair process does not relate to the ratio of formation of dicentric chromosome and translocation (Simpson et al .,1994). The populations of first and second mitotic cells were evaluated by FPG method in present experiment. The frequency of second mitosis was significantly less $\left(0.1-2.1 \%\right.$ in ${ }^{252} \mathrm{Cf}$ neutrons, and $0.4-5.2 \%$ in
${ }^{60} \mathrm{Co} \mathrm{Y}$-rays, and ${ }^{137} \mathrm{Csy}$-rays). Therefore, there is almost no possibility that existing second mitotic cells could influence for the chromosomal aberration yield of dicentric and rings.

The present study reveals that dicentric chromosomes were induced by ${ }^{252} \mathrm{Cf}$ neutrons at a rate 1.3-2.0 times higher than that of ${ }^{60} \mathrm{Co} \gamma$-rays and ${ }^{137} \mathrm{Cs} \mathrm{y}$-rays, indicating that increase in LET results in higher frequency of dicentric chromosome formation per unit dose. Thus physical dose and its RBE value differ for high LET radiation compared to that of low LET radiation. It remains to be resolved by means of molecular biological techniques why high LET radiation induced a higher number of dicentric chromosomes and also why exposure of low dose rate with high LET radiation induced higher percentage of translocation. Proteins associated with G2 block and mitotic apparatus, and chromosomal localization in the cell nucleus at G2 or $\mathrm{M}$ phase may be related to these phenomena. The ratio of translocations to dicentric chromosomes was 1:1 only when measured shortly after acute exposure to low LET radiation. In such cases of a 1:1 ratio, the FISH method would be applicable to estimate the translocation rates from the results of incidence of dicentric chromosomes. These results provide useful information for the re-evaluation of the biological effects of neutrons with low dose rate.

\section{Acknowledgements}

We thank Dr. T. Kyo, Hiroshima Red Cross Hospital for providing normal bone marrow samples. We are grateful to Mr. S. Takeoka, K. Kitagawa and S. Suga of the Radiation Research Center for Frontier Science, Research Institute for Radiation Biology and Medicine, Hiroshima University.

\section{References}

1. Ban S, Donovan MP, Cologne JB and Sawada $S$ (1991) Gamma-ray and fission neutroninduced micronuclei in PHA stimulated and unstimulated human lymphocytes. J. Radiat. Res. 32,13-22.

2. Ban S, lida S, Awa AA and Sawada S (1987) Lethal and mutagenetic effects of ${ }^{252} \mathrm{Cf}$ radiation in cultured human cells. Int. J. Radiat. Biol. 52, 245-251.

3. Bauchinger $M$, Schmid $E$, Zitzelsberger $H$, Braselmann $H$ and Nahrstdt $U$ (1993) Radiation-induced chromosome aberrations analyzed by two-colour fluorescence in situ hybridization with composite whole chromosome-specific DNA probes and a pancentromeric DNA probe. Int. J. Radiat. Biol. 64,179-184. 
4. Brenner D and Hall EJ (1990) The inverse dose-rate effect for oncogenic transformation by neutrons and charged particles: a plausible interpretation consistent with published data. Int. J. Radiat. Biol. 58, 745-758.

5. Doggett NA and McKenzie WH (1983) An analysis of the distribution and dose response of chromosome aberrations in human lymphocytes after in vitro exposure to ${ }^{137}$ Cesium gamma radiation. Radiat. Environ. Biophys. 22, 33-51.

6. Fernandez JL, Campos A, Goyanes V, Losada C, Veiras C and Edwards AA (1995) X-ray biological dosimetry performed by selective painting of human chromosomes 1 and 2 . Int. J. Radiat. Biol. 67,295-302.

7. Fujita S, Kato H and Schull WJ (1991) The $\mathrm{LD}_{50}$ associated with exposure to the atomic bombing of Hiroshima and Nagasaki. J. Radiat. Res. Suppl 154-161.

8. Gajendran N (2007) Cytogenetic aspects of neutron-induced cellular response. Indian J. Sci. Technol. 1(1), 1-15.

9. Hansmann I, Meyding U and Virsik RP (1983) $X$-ray induced reciprocal translocations and dicentrics in human $\mathrm{G}_{0}$ lymphocytes. Int. J. Radiat. Biol. 43, 91-93.

10. Hieber L, Ponsel G, Roos H, Fenn S, Fromke $E$ and Kellerer AM (1989) Absence of a dose-rate effect in the transformation of C3H10T1/2 cells by a -particles. Int. J. Radiat. Biol. 52,859-869.

11. Hill CK, Buonaguro FM, Myers CP, Han A and Elkind MM (1982) Fission-spectrum neutrons at reduced dose rates enhance neoplastic transformation. Nature 298, 67-69.

12. Hill CK, Carres BA, Han A and Elkind MM (1985) Neoplastic transformation is enhanced by multiple low doses of fission-spectrum neutrons. Radiat. Res. 102,404-410.

13. Hoshi M, Takeoka S, Tsujimura T, Kuroda T, Kawami M and Sawada S (1988) Dosimetric evaluation of ${ }^{252} \mathrm{Cf}$ beam for use in radiobiology studies at Hiroshima University. Phys. Med. Biol. 33, 473-480.

14. ICRP1991 International Commission on Radiation Protection (1991) Recommendations of the International Commission on Radiological Protection. ICRP Publication 60 Annals of the ICRP 21(1-3).

15. Kamada N, Shigeta C, Kuramoto A, Munaka M, Yokoro K, Niimi M and Aisaka C (1989) Acute and late effects of atomic bomb radiation studies in a group of young girls with a defined condition at the time of bombing. J. Radiat. Res. 30, 218-225. http://www.indjst.org

Vol.2 No 1 (Jan. 2009)
16. Kanda R and Hayata I (1996) Comparison of the yields of translocations and dicentrics measured using conventional Giemsa staining and chromosome painting. Int. J. Radiat. Biol. 69, 701-705.

17. Kovacs MS, Evans JW, Johnstone IM and Brown JM (1994) Radiation-induced damage, repair and exchange formation in different chromosomes of human fibroblasts determined by fluorescence in situ hybridization. Radiat. Res. 137, 34-43.

18. Kubota N, and Hill CK (1989) Dose rate effect of fission-spectrum neutrons on mutation induction in Chinese hamster cell and human diploid fibroblasts. Sci. Pap. Inst. Phys. Chem. Res. 83,25-30.

19. Lloyd DC, Purrott RJ, Reeder E J, Edwards AA and Dolphin GW (1978) Chromosome aberrations induced in human lymphocytes by radiation from ${ }^{252} \mathrm{Cf}$. Int. J. Radiat. Biol. 34, 177-186.

20. Lucas JN (1998) Cytogenetic signature of ionizing radiation. Int. J. Radiat. Biol. 73, 15-20.

21. Lucas JN, Chen AM and Sachs RK (1996) Theoretical predictions on the equality of radiation-produced dicentrics and translocations detected by chromosome painting. Int. J. Radiat. Biol. 69, 145-153.

22. Lucas JN, Poggensee M and Straume T (1993) Translocations between two specific human chromosomes detected by three-color "chromosome painting". Cytogenet. Cell Genet. 62, 11-12.

23. Lucus JN, Awa A, Straume T, Poggensee M, Kodama Y, Nakano M, Ohtaki K, Weier U, Pinkel D, Gray J and Littlefield G (1992) Rapid translocation frequency analysis in humans decades after exposure to ionizing radiation. Int. J. Radiat. Biol. 62, 53-63.

24. Miller RC, Brenner DJ, Grear, CR, Komatsu K, Marino SA and Hall EJ (1988) Oncogenic transformation by the fractionated doses of neutrons. Radiat. Res. 114, 589-598.

25. Miller RC, Brenner DJ, Randers-Pehrson G, Marino SA and Hall EJ (1990) The effects of the temporal distribution of dose on oncogenic transformation by neutrons and charged particles of intermediate LET. Radiat. Res. 124, S62-S68.

26. Morton NE (1991) Parameters of the human genome. Proc Natl Acad Sci, USA 88,7474-7476.

27. Nakamura N and Akiyama M (1988) Cell death of human peripheral lymphocytes by tritiated water and RBE. Report of the Grant in Aid for Energy Research. pp: 115-116.

28. Nakamura N and Sawada S (1988) Reversed 
dose-rate effect and RBE of 252-californium radiation in the induction of 6-thioguanineresistant mutations in mouse L5178Y cells. Mutat. Res. 201, 65-71.

29. Nakanishi M, Tanaka K, Shintani T,Takahashi $T$ and Kamada N (1999) Chromosomal instability in acute myelocytic leukemia and myelodysplastic syndrome patients among atomic bomb survivors. J. Radiat. Res. 40, 159-167.

30. Nakano M, Nakashima E, Pawel J, Kodama Y and Awa A (1993) Frequency of reciprocal translocations and dicentrics induced in human blood lymphocytes by X-irradiation as determined by fluorescence in situ hybridization. Int. J. Radiat. Biol. 64, 565-569.

31. Natarajan AT, Balajee AS, Boei JJWA, Chatterjee S, Darroudi F, Grigorova M, Noditi $\mathrm{M}$, Oh HJ, Slijepcevic $P$ and Vermeulen S (1994) Recent developments in the assessment of chromosomal damage. Int. J. Radiat. Biol. 66, 615-623.

32. Natarajan AT, Vyas RC, Darroudi $F$ and Vermeulen $S$ (1992) Frequencies of $X$-ray-induced chromosome translocations in human peripheral lymphocytes as detected by in situ hybridization using chromosomespecific DNA libraries. Int. J. Radiat. Biol. 61,199-203.

33. Perry P and Wolff S (1974) New Giemsa method for the differential staining of sister chromatids. Nature 251,156-158.

34. Rossi HH and Kellerer AH (1986) The dose rate dependence of oncogenic transformation by neutrons may be due to variation of response during the cell cycle. Int. J. Radiat. Biol. 50, 353-361.

35. Schmid E, Zitzelsberger $H$, Braselmann $H$, Gray JW and Bauchinger M, (1992) Radiation-induced chromosome aberrations analyzed by fluorescence in situ hybridization with a triple combination of composite whole chromosome-specific DNA probes. Int. J. Radiat. Biol. 62, 673-678.

36. Shigeta C, Tanaka K, Oguma N, Kamada N and Ohkita T (1988) Radiation sensitivity of human bone marrow fibroblast colony forming unit (CFU-F) to various radiation sources. $J$. Radiat. Res. 29,182-188.

37. Simpson PJ and Savage JRK (1994) Identification of X-ray-induced complex chromosome exchanges using fluorescence in situ hybridization: a comparison at two doses. Int. J. Radiat. Biol. 66, 629-632.

38. Straume T and Lucas JN (1993) A comparison of the yields of translocations and dicentrics measured using fluorescence in situ hybridization. Int. J. Radiat. Biol. 64,185-187.

39. Tanaka K, Gajendiran N, Endo S, Komatsu K, Hoshi M and Kamada N (1999) Neutron energy-dependent initial DNA damage and chromosomal exchange. J. Radiat. Res. 40, Suppl, 31-44.

40. Tanaka K, Popp S, Fischer C, van Kaik G, Kamada N, Cremer T and Cremer C (1996) Chromosome aberration analysis in atomic bomb survivors and Thorotrast patients using two- and three-colour chromosome painting of chromosomal subsets. Int. J. Radiat. Biol. 70,95-108.

41. Tauchi $H$, Nakamura $N$, Komatsu $K$ and Sawada S (1996) Accumulation of cells at $\mathrm{G}_{2} / \mathrm{M}$ stage by low dose-rate irradiation renders the cell population more susceptible to the subsequent induction of 6-thioguanine -resistant mutations by ${ }^{252} \mathrm{Cf}$ fission neutrons. $J$. Radiat. Res. 37,49-57.

42. Tucker JD, Morgan WF, Awa AA, Bauchinger $M$, Blakey $D$, Cornforth MN, Littlefield LG, Natarajan AT and Shasserre C (1995) A proposed system for scoring structural aberrations detected by chromosome painting. Cytogenet. Cell Genet. 68, 211-222.

43. Tucker JD, Ramsey MJ, Lee DA and Minkler JL (1993) Validation of chromosome painting as a biodosimeter in human peripheral lymphocytes following acute exposure to ionizing radiation in vitro. Int. J. Radiat. Biol. 64, 27-37.

44. US-JAPAN (1987) Joint Reassessment of Atomic Bomb Radiation Dosimetry in Hiroshima and Nagasaki, edit. by E C Roesch, (Radiation Effects Research Foundation) Volume 1.

45. Whaley JM and Little JB (1990) Molecular characterization of hprt mutants induced by low- and high LET radiations in human cells. Mutat. Res. 243, 25-45. 